\title{
How Personality Shapes Study Location Choices
}

\author{
Reinhard A. Weisser ${ }^{1}$
}

Received: 9 March 2018 / Published online: 20 March 2019

(c) The Author(s) 2019

\begin{abstract}
In this paper I investigate undergraduate students' discrete location choices in presence of a plethora of potential destinations and psychic costs. I demonstrate how enrolment into institutions of tertiary education is influenced by personality and social preferences. More importantly, these individual traits are found to affect the valuation of location-specific conditions in alternative study locations. Eventually, the relevance of location attributes, such as urban or labour market characteristics, varies substantially with respect to distance and individuals' personality. This has direct implications for student recruitment, since prospective students display distinct geographic sorting patterns along these traits: students featuring higher levels of patience integrate post-graduation opportunities into their decision-making. As a consequence, institutions in economically less prosperous regions might attract a specific subset of the overall student population, which might also have repercussions on student performance.
\end{abstract}

Keywords Student mobility · University enrolment choice $\cdot$ Geo-referenced data · Personality $\cdot$ Conditional logit model

JEL Codes R23 $\cdot$ I23

\section{Introduction}

How to find one's place in a world full of opportunities and alternatives? In a literal sense, this question boils down to a discrete location choice among a plethora of alternatives at different levels, such as countries, states, cities, boroughs or streets. This question is relevant for any individual, but especially for those starting into a new stage of life, such as taking up academic training at a university.

A lot is known about external factors attracting individuals to specific places or individual attributes fostering mobility on an abstract level. Surprisingly little is known about how

Electronic supplementary material The online version of this article (https://doi.org/10.1007/s1116 2-019-09550-2) contains supplementary material, which is available to authorized users.

Reinhard A. Weisser

r.weisser@qmul.ac.uk

1 School of Economics and Finance, Queen Mary University of London, London, UK 
these influential factors interact or how personality and social preferences exactly affect perceived costs of migration, be it in the general or the student population.

These interactions are the pivotal elements of this study where I demonstrate that the relevance of location-specific attributes in a discrete choice framework varies substantially with respect to heterogeneous personality profiles. Personality profiles within the context of this research comprise risk attitude, time and social preferences as well as the Big-Five personality traits, known from the psychological literature (cf. McCrae and Costa Jr. 2004). ${ }^{1}$ Drawing upon a unique survey on student mobility (MESARAS 2013; Weisser 2016a), which provides both information on personality profiles and on the process of location choice, I can provide a new perspective on the university choice process.

Beyond that, my research also contributes to the literature on long-term geographic sorting patterns of tertiary educated individuals, since the choice of a study location is a relevant precursor of subsequent location choices in the tertiary educated labour force (Belfield and Morris 1999; Groen 2004; Busch and Weigert 2010). Another contribution of this work is to shed some light on intra-national student mobility outside the Anglo-American realm, which is a rather sparsely discussed phenomenon (cf. Prazeres 2013).

My analyses rely on observed location choices of undergraduate students enrolling into economics or business programmes at higher education institutions, choosing amongst 164 study locations in Germany. ${ }^{2}$ To accommodate the size of the destination space and to account for heterogeneous individuals, I apply a conditional logit model for heterogeneous agents. This model might be susceptible to varying definitions of the underlying choice set (Hicks and Strand 2000; Carson and Louviere 2014), and thus to the level of available information on the choice process itself. Therefore, one aspect of my empirical analysis is to integrate information on considered alternatives during the university application process.

Focusing on university choices in a medium sized country, like Germany, has several advantages: For one, the German higher education sector is of substantial size and offers internationally competitive programmes. This fosters the external validity of my results. At the same time it is possible to include virtually the complete relevant higher education sector into the analysis while narrowing down the set of potential destinations to cities for which a wide range of location-specific urban and geographic indicators is available. This provides refined insights into complex behavioural processes while maintaining analytical tractability. Another merit of using the German setting is related to the mostly non-competitive student recruitment of universities. The publicly funded universities do not engage in pronounced marketing activities in order to maximise their revenues from student fees. Therefore, this study's findings prove informative with respect to students' choice processes without the distortions ensuing hard to measure marketing activities.

Eventually, my research informs about heterogeneous study location preferences which are related to personality and geography. The core findings will contribute to our understanding of what type of students is attracted to a university in a specific urban or geographic setting, and therefore how to boost enrolment.

\footnotetext{
${ }^{1}$ Time preferences refer to individual patience, whereas the Big-Five personality traits comprise the following traits: openness, conscientiousness, extraversion, agreeableness and neuroticism.

${ }^{2}$ Within this work I am using the terms 'university', 'institution of higher education' or 'institution of tertiary education' interchangeably. The mentioned programmes refer to Bachelor programmes with a clearly defined study subject.
} 
The remainder of this paper is organised as follows: The "Study location choices in the related literature" section provides an introduction to the current state of knowledge. Details of the German higher education system and the choice process are illustrated in the section "Study location choices in Germany: Institutional and empirical setting", also introducing this study's data source. In the section "Heterogeneous agents in a random utility framework", I outline the basic econometric model and an augmented model to address econometric caveats. Baseline estimation results and personality-related sorting patterns are discussed and illustrated in the "Empirical results" section, which also includes a variety of robustness checks. The "Conclusion" section summarises this paper's main insights and points out potential implications for student recruitment.

\section{Study Location Choices in the Related Literature}

Understanding enrolment into tertiary education has been an ample field of research. Within this field, a number of studies applied discrete choice models in order to examine students' choices amongst the vast number of available institutions of higher education. Some of these studies explicitly investigated university choices in a geographic context, also differentiating between heterogeneous socio-demographic (Kohn et al. 1976) and socio-economic backgrounds. Referring to distance to university as one of the most prominent features of geography, Long (2004) stressed in a multi-cohort analysis of college enrolment choices an attenuating deterring effect of distance across all income and ability groups over time. Tuition costs affected the choice of a specific college to a lesser extent for younger cohorts, though individuals from low income backgrounds still displayed a comparable sensitivity. This trend of relatively lower importance of tuition costs continued in the 2000s (Skinner 2019), whereas the importance of distance did not decline over time. The sensitivity of individuals from economically less favoured households was also confirmed by Avery and Hoxby (2004) investigating the sensitivity of college choice with respect to financial aid.

Referring to the impact of demographic characteristics in the domain of discrete migration choices, female graduates were found to opt more frequently into the 'option' of being a repeat-migrant, first to university and subsequently to another region (Faggian et al. 2007). Young Germans were found to select themselves into regions offering better economic perspectives or quality of life (Schneider and Kubis 2010), whereas university graduates favour destination regions which are similar to their origin regarding spoken dialect or settlement type (Buenstorf et al. 2016).

Oosterbeek et al. (1992) examined choices from the set of universities offering economics programmes in The Netherlands. Most notably, the moderate positive effects of university-specific expected life-time earnings on selection probabilities were not robust with respect to the inclusion of individual-specific attributes or a university city's attractiveness - utility seemed to be predominantly shaped by preferences beyond earnings.

Separating attendance and location choice, Montgomery (2002) highlighted that individual ability fostered attendance. A general preference for schools with a more able student body or a top ranking position could be observed in the school choice process. Final school choice, however, was heavily affected by geographic proximity although it was not relevant for stated 'first choice' schools.

This general dominance of the attribute 'distance' is one of the common findings in the literature related to geographic mobility. Plausibly, costs of any type of migration tend to 
increase in distance, e.g. due to rising transportation or transaction costs. The resulting distance deterrence effect can be observed for internationally mobile students (Rodríguez González et al. 2011; Brezis and Soueri 2011; Perkins and Neumayer 2014; Beine et al. 2014) and in case of intra-national student mobility (McHugh and Morgan 1984; Leppel 1993; Alm and Winters 2009; Cooke and Boyle 2011). Moreover, the magnitude of the distance deterrence effect for university selection varies across socio-economic or sociodemographic groups (Jepsen and Montgomery 2009; Gibbons and Vignoles 2012).

Costs of choosing a more distant university may also reflect non-pecuniary aspects, such as psychic costs (Sjaastad 1962) originating from social or place attachment. Ultimately, these psychic costs can be quantified, since they "can be transformed into permanent transportation cost by figuring the needed frequency of visits to the place of origin so as to negate the agony of departure from family and friends" (Schwartz 1973, p. 1161). Although this points to the relevance of social preferences and personality in the domain of student mobility, there is (to the best of my knowledge) no quantitative research dedicated to integrating personality traits into models of university choice. Only in recent years, some research emerged in the context of labour mobility where personality was explicitly factored in —and found to be relevant (Jokela 2009; Jaeger et al. 2010; Canache et al. 2013). This is largely due to a lack of data on mobile individuals also providing information on preferences and personality.

Another important determinant of location choices are place-specific amenities and labour market conditions (Roback 1982; Clark and Cosgrove 1991; Whisler et al. 2008; Schündeln 2014; Davies et al. 2001). These factors are also relevant for the subpopulation of students enrolled in tertiary education: McHugh and Morgan (1984) and Dotti et al. (2013) presented evidence that student migration is influenced by economic conditions in the destination state. At the same time, students seem to be attracted to destinations with better amenities (Mixon and Hsing 1994³; Cooke and Boyle 2011), and thus they behave similarly to non-student migrants.

While mobility-related decisions in the general and the student population may have a lot in common, there is a peculiarity related to university choices, and thus to study location choice: the relevance of information on institutional quality. Students can be selective, yet some choose to migrate in order to attend highly ranked institutions, others due to availability of admission (Mixon and Hsing 1994; Cooke and Boyle 2011). The potential impact of a ranking on preferences may also vary across types of university, whereas higher research activities may even deter potential students (Drewes and Michael 2006). Regarding university choice in a relatively small and densely populated country, such as The Netherlands, Sá et al. (2004, p. 389) concluded that "prospective university students are mainly guided by consumption motives, [...] because the quality of educational programmes does not play a significant role in their choice behaviours". There is also evidence in favour of students choosing study places mostly based on availability and costs (Faggian and McCann 2006). Ultimately, the evidence on the impact of institutional quality for the decision-making process is mixed.

\footnotetext{
${ }^{3}$ Specific sportive activities constitute relevant consumption factors for students in their approach.
} 


\section{Study Location Choices in Germany: Institutional and Empirical Setting}

\section{Tertiary Education in Germany: Institutions and Enrolment}

Around winter 2013/2014, the reference point of this study, prospective academics could enrol at one of 399 officially recognised institutions of higher education (HE) in Germany, offering 9800 undergraduate programmes in total (HRK 2015). In general, the German HE market can be seen as rather consolidated: during the last two decades there have been no exits, the emergence of new larger institutions is mostly related to the reorganisation of existing universities. Thus, the number of comprehensive universities or universities of applied sciences has been stable over years. ${ }^{4}$ The majority of newly established institutions, in turn, are private and feature low enrolment numbers.

Overall, there were 238 public universities with an average enrolment of 10,228 students. With $92.6 \%$ of all students enrolled, public universities represent the backbone of the German HE system. Furthermore, there were 121 private institutions and 40 churchrelated HE institutions, with an average enrolment of 1424 and 809 students respectively.

In winter 2013/2014, 2.6 million undergraduate and post-graduate students were enrolled at German HE institutions (Destatis 2014a), which has been expanding by almost $30 \%$ over the previous 10 years. The share of foreign students amounted to $11.5 \%(301,000$ students). ${ }^{5}$

Within the European Union, the German tertiary education system is the largest in terms of overall enrolment, reflecting the total number of students studying in a Bachelor, Master or doctoral programme (ISCED levels 6-8): From 2013 to 2015 it is, on average, $40 \%$ larger than the UK sector (OECD 2018). In comparison to the US higher education sector, and referring to studies on the Bachelor, Master and doctoral level, enrolment in Germany amounts to approximately one quarter.

In regard to study location choices, the actual number of alternative destinations (relating to a university's main campus) can be narrowed down to 171 cities in Germany (Fig. 1). University cities are relatively evenly spread across the country, with the exemption of some sparsely populated regions in eastern Germany.

If we restrict the set of potential study destinations to universities offering economics or business programmes, the most frequently chosen programmes amongst the population of freshmen in 2013 (Destatis 2014a), 164 distinct study locations remain (Fig. 2). Based on the country's geographic size, the relatively even distribution of universities across space and the available (public) transportation system, German students do not face so-called 'education deserts', as have been documented in the US (Hillman 2016). Their choices should therefore not be limited by physical inaccessibility.

With respect to general accessibility, two major aspects of the German HE system have to be mentioned. The first thing to note is that, in contrast to the Anglo-American realm, tuition fees never played an important role. For over 30 years, no formal tuition fees have

\footnotetext{
4 Traditionally, there has been a distinction between comprehensive universities and more applied universities. The latter tend to be somewhat smaller, more focused on specific subject groups, less research-focused and only some amongst them have been granted the right to award $\mathrm{PhDs}$ in recent years. In addition to these two major groups there exists a number of art colleges and colleges of public administration. Their joint enrolment share is below three percent.

${ }^{5}$ Four years later, overall enrolment increased by another 8.6 percent; enrolment of foreign students rose by $24.4 \%$ (Destatis 2018).
} 
been raised at public universities. After a revision of the Framework Act for Higher Education in 2002, the federal states could decide individually whether to levy tuition fees or not. From 2005 onwards, West German states formally introduced tuition fees. In contrast to fees in the Anglo-American realm, they were relatively low, i.e. not more than 500 Euro per 6 month semester (ca. 570 USD in today's terms). As a consequence of student and public opposition, these tuition fees have been abolished until 2014 . $^{6}$ Since then, and as before, the only directly study-related fees are the so-called semester fees, which comprise basic administration fees, contributions to student unions and student services, as well as the student ticket for public transportation. These semester fees vary across universities, yet remain typically in a range of 200-400 Euro. To fund their expenditures students can apply for the means-tested Federal Training Assistance, which is part grant, part interest free loan. In 2013, 666,000 students were supported and the average amount students received was 446 Euro per month (Destatis 2014b). This implies that, aside from the opportunity costs of studying, the financial burdens for students at German HE institutions are comparably low. Ultimately, the direct costs of studying in Germany are primarily determined by the study location choice and the related living expenses.

The second important aspect is the admission process. Aside from studies in medicine and pharmacy, the selection and admission process is subject to university- or departmentspecific regulations. There are no application fees and students can apply directly at as many institutions as they wish. The principal admission criterion is the so-called university entrance certificate (UEC), obtained after partly standardised examinations at the end of the secondary education phase. ${ }^{7}$ Without this UEC enrolment at a German university is not possible in general. In some programmes, an extended application process may require an additional documentation of qualifications or interest in the subject. For most undergraduate programmes, especially the most popular ones, the average mark of the UEC is the relevant factor. A better average mark increases the likelihood of admission. Depending on internal and political targets, a so-called 'numerus clausus' is determined for most programmes: applicants with a better average UEC grade are offered a study place, those below this threshold are rejected. This threshold, however, is not absolute since applicants can accumulate 'waiting semesters': For each semester in between the year the UEC was obtained and the application, prospective students receive a bonus on their UEC grade. Therefore, even if someone missed the 'numerus clausus' by a margin, there is a chance of admission.

In summary, the German university landscape represents a relatively large and developed HE sector, possibly rather representative for tertiary education sectors in middle and northern Europe. The absence of tuition fees and the availability of training assistance implies that the choice of a study location is not predominantly due to credit constraints but related to individual preferences.

\footnotetext{
${ }^{6}$ Some states still charged tuition fees for long-term students (those who are four to six semester above the usual duration of study) or those enrolling in a second degree programme (the first post-graduate programme does not fall under this definition).

7 Since education is subject to state legislation, there exists a large variation between (and often even within) states. Some states have a centralised examination where all pupils have to pass identical tests in core subjects (maths, German, a foreign language, natural sciences). In others, it is merely required that the level of difficulty is comparable. The overall mark of the university entrance certificate is, however, not solely determined by these final examinations but also by scholastic achievements in the previous (two) year(s).
} 
Fig. 1 Proportional geographic distribution of German HE institutions. Note: The relative size of the dots corresponds to the number of $\mathrm{HE}$ institutions in a respective city

Alternatives at the application stage

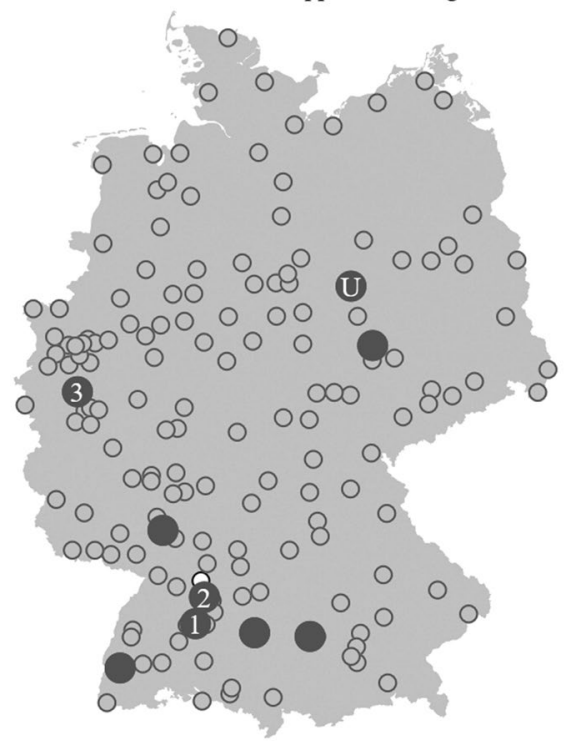

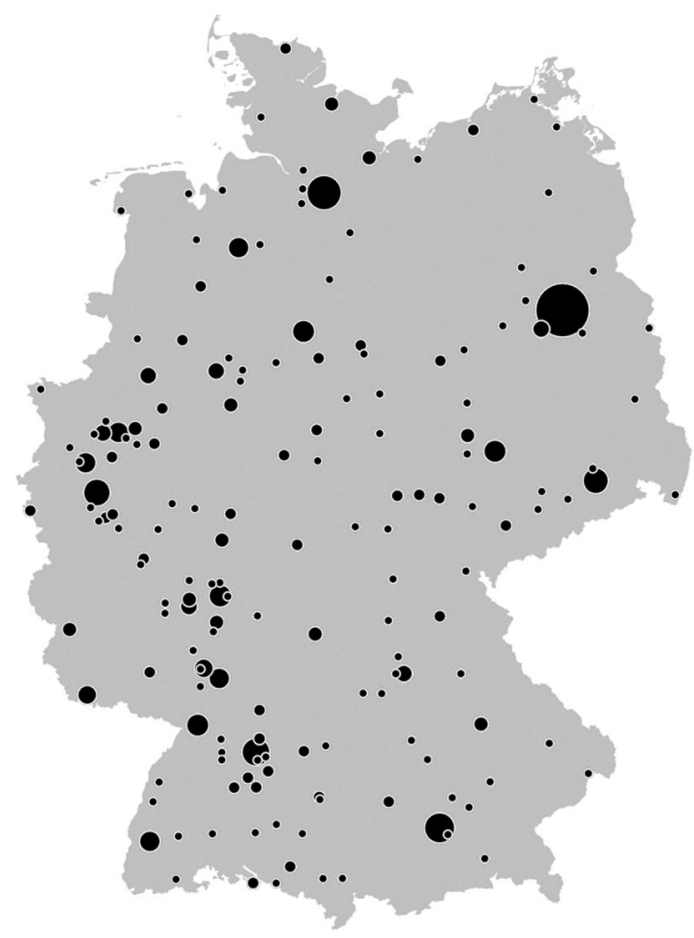

Alternatives at the enrolment stage

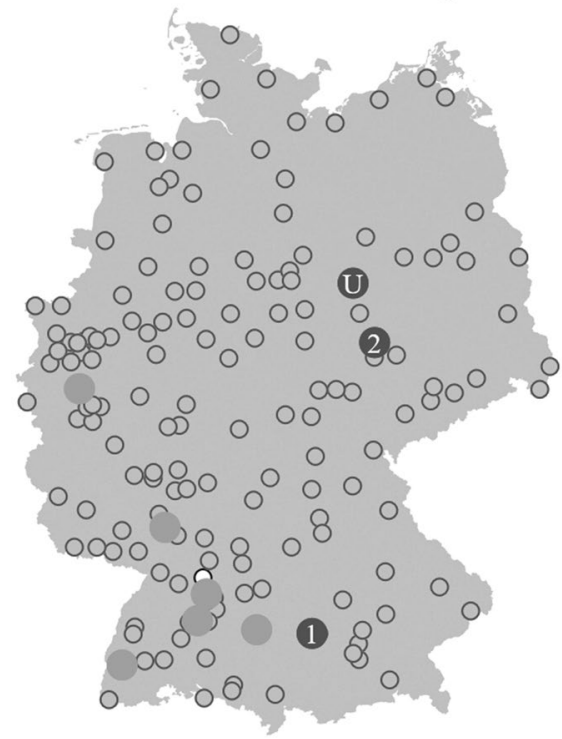

$\begin{array}{ll}\circ \text { home } & \text { irrelevant } \\ \text { no admission } & \text { admission }\end{array}$

Fig. 2 Decision-makers' alternatives. Note: The left panel depicts the application stage (complete destination space and sent applications for a fictitious individual), the right panel illustrates the remaining alternatives at the enrolment stage 


\section{Microdata on Decision-Makers and Their University Choice Sets}

This research draws on a cross-sectional survey on "Mobility, Expectation, Self-Assessment and Risk Attitude of Students" (MESARAS 2013; Weisser 2016a), which provides detailed information on individual characteristics and preferences, choice sets within the application process and further relevant geographic reference points.

The survey's target group composed of undergraduate university students, who started an economics or business programme at one of seven universities in northern and middle Germany in October 2013. ${ }^{8}$ These seven public universities represent the German HE sector with respect to subject variety, cities (rural, urban and metropolitan) and states (East and West Germany) they are located in. These seven university locations are also highly representative of typical university districts (cf. Fig. A.1 in the electronic supplementary material). Figure A.2 documents that the universities in the sample (5000-44,000 students) are also highly representative regarding overall student enrolment at comprehensive universities in Germany.

The survey was implemented as self-administered questionnaire and directly integrated either into the orientation week or a lecture in the first two weeks of the semester. Using administrative enrolment data, a high degree of representativeness with respect to the programme specific population could be established (Weisser 2016b). ${ }^{9}$ Across the seven participating departments, the sample comprises $68.3 \%$ of all enrolled first semester undergraduate students in the winter semester 2013/2014. Further analyses indicate that this study's sample is also widely representative of the more general population of beginning students enrolling in economics or business studies and the overall student population in Germany. ${ }^{10}$

The MESARAS survey focused on beginning students enrolling in economics or business programmes for methodological and practical reasons: For one, economics and business programmes are represented at almost all universities or universities of applied sciences. This restriction ensures that chosen destinations are actually outcomes from a choice process and not mostly predetermined by the interest in an exotic programme only available at few institutions. At the same time, the programmes' popularity ensures the realisation of a sample of sufficient size to robustly estimate complex discrete choices. Another reason for targeting students in these programmes, offering a rather diverse curriculum, is that they may appeal to individuals with diverse interests. Thus, except for basic aspects of

\footnotetext{
${ }^{8}$ Students enrolled at the following universities participated (sample size in brackets): Bielefeld University (173), Clausthal University of Technology (59), TU Dortmund University (257), Martin-Luther-University Halle-Wittenberg (222), Leibniz Universitaet Hannover (281), University of Muenster (603) and Otto von Guericke University Magdeburg (266). These universities are located in three German states (Lower Saxony, North Rhine-Westphalia, Saxony-Anhalt).

9 In order to evaluate the sample's representativeness, I compared the distributions of age, gender, study programme and former scholastic achievement. A complete overview of conceptual details and descriptive statistics can be found in Weisser (2016b).

${ }^{10}$ Referring to the two largest subject-specific groups in the study sample, the share of male students in the population of Economics and Business students is 54.6\% (Destatis 2014a; study sample: $54.1 \%$ ), whereas the population share of male students in a business programme is $51.2 \%$ (study sample: $53.9 \%$ ). Using further information on the population of all (beginning) students from Scheller et al. (2013) and Middendorff et al. (2013), I can also document a high degree of representativeness along the following characteristics: age, UEC grade, completed vocational training, available monthly budget and being enrolled at the preferred university.
} 
self-selection into a special study programme, the respondents can be assumed to be rather representative for young adults at the beginning of their (academic) career.

For the purpose of this study, another design related restriction led to the exclusion of study programme changers to ensure that all subjects made a choice with respect to a study location for the first time. Students from abroad, i.e. those who graduated from high school in another country, were also excluded from the sample since previous geographic anchor points are too imprecise. Eventually, the relevant study target sample comprised 1861 individuals.

These newly enrolled individuals could choose amongst 164 potential study locations with at least one institution of higher education offering economics or business programmes. Based on curriculums' similarities, the following study programmes are rated as economics or business programmes: Business Studies, Economic Studies, International Management and Economics and Business. Furthermore, Business Informatics, Engineering Economics and Economic Policy Journalisms are included as highly related programmes. $^{11}$

Figure 2 displays the geographic distribution of the 164 alternative study locations, defining the complete destination space for anyone who is interested in an economics or business programme at a German university. The left panel refers to the application stage of a figurative individual, the right panel shows the corresponding outcome after universities' admission processes have imposed some further restrictions on the set of potential destinations.

The hollow circles represent all potential alternatives that have never been considered, whereas the filled circles indicate a study location this figurative individual has applied for. Aside from the eventually chosen alternative (labelled ' $U$ '), the three most preferred alternatives at each stage are observed in the survey as well.

Among the study target sample, 69\% actually had an alternative admission for an economics or business programme. Around $55 \%$ in this group chose, eventually, the closest available alternative. Going one step back and focusing on the locations initially applied for, $23.2 \%$ sent out only a single application. $11.6 \%$ selected two potential locations, $19.4 \%$ applied at institutions in three distinct locations. The majority (45.9\%) included into their application set at least four alternative destinations.

At this initial stage, prospective academics in the sample considered many potential destinations further away from their origin, the latter identified as the city they graduated from high school. Metropolitan areas, such as the city states Berlin or Hamburg, were frequently mentioned as most preferred study alternatives.

In the end, the applicants displayed a distinct tendency to enrol at an institution in relative proximity to their origin. On average, respondents chose a study location within 97.15 $\mathrm{km}$ of their origin. ${ }^{12}$ There are, however, remarkable differences of observed mobility with respect to varying personal characteristics (Table 1). Least patient individuals enrolled at closer institutions ( $92.5 \mathrm{~km}$ distance on average) in comparison to those at the other end of the scale (115.7 $\mathrm{km}$ on average). A similar discrepancy can be observed between

\footnotetext{
11 The relevance of the definition regarding what counts as economics or business programme is investigated in a robustness check.

${ }^{12}$ Within this research, distance is defined as the distance between the centroids of the postal code area of origin and the postal code area a university is located in. It is calculated as geodetic distance, which corresponds to the length of the shortest curve between these two points on the surface of an ellipsoidal approximation of the earth.
} 
individuals with a low level $(87.9 \mathrm{~km})$ and a high level risk attitude $(106.5 \mathrm{~km})$. Moreover, those expressing a strong preference for proximity to family behave accordingly when it comes to the choice of a study location.

\section{Characteristics of Study Location Alternatives}

Each study location offers a variety of amenities and other place-based characteristics, which might be relevant for the study location choice process. Within this study, I will focus on several urban statistics (population size, population density, GDP per capita, price level proxy), labour market characteristics (unemployment rates, high-skilled employment rates) and quality of life measures (recreational area, accessibility of urban amenities). All location-specific data originates from the INKAR online database (BBSR 2014) and refers to the district level. ${ }^{13}$ The reference year is 2012 , which is the last complete year before respondents made their decision.

Figure A.1 (in the electronic supplementary material) illustrates kernel density estimates for ten place-based characteristics, distinguishing between the 151 districts hosting a university (offering an economics or business programme) and those 250 districts without such a university. In general, the distribution of location-specific attributes is rather comparable across these two groups. There are three easily discernible, yet hardly surprising exemptions: GDP per capita and high-skilled employment rates in districts hosting a university are higher, and university districts are more likely in the vicinity (or part) of urban agglomerations. ${ }^{14}$

There is some descriptive evidence that prospective students might indeed be sensitive with respect to location-specific characteristics and distance at the application stage. To highlight this, I split the set of 164 alternative study locations, situated in the above mentioned 151 districts, into two subsets: the first subset includes all study locations which either were eventually chosen or belonged for at least one per cent of the subjects to the three most preferred considered locations at the application stage. This subset of preferred destinations contains 33 study locations. The remaining 131 study locations were either not considered as the most preferred alternatives (of at least one per cent of the respondents) or have not been considered at all. ${ }^{15}$

Figures 3 and 4 display for all 164 potential destinations bivariate kernel density estimates of one selected location-specific condition (on the vertical axis) and individuals' potential mobility (on the horizontal axis), measured as average distance to individuals' origins. Such bivariate representations reflect a trade-off between distance-related costs of migration and potential gains, e.g. from obtaining access to a certain location-specific amenity. The left panels refer to locations that are in the subset of preferred study location and the right panels represent locations which are not in the subset of preferred

\footnotetext{
13 The publicly accessible INKAR online database provides detailed information on a variety of regional indicators, e.g. on the state or district level, covering the whole of Germany. Available series include, amongst others, regional economic and social statistics, land use, infrastructure and mobility indicators.

14 Which can be inferred based on the lower average time it takes to reach the next agglomeration centre.

15 Within the study sample, 63 out of 164 potentially relevant study locations were not considered at all by the majority of respondents. There might have been someone who applied at institutions in those locations, yet they were not part of the most preferred alternatives, and thus not recorded (cf. Fig. 2). Aspects of choice set misspecification are examined in the "Robustness checks" section.
} 
Table 1 Observed mobility (in $\mathrm{km})$ and personality traits

\begin{tabular}{lclr}
\hline & \multicolumn{3}{l}{ Trait categorisation } \\
\cline { 2 - 4 } & Low & Medium & High \\
\hline Risk attitude (career domain) & 87.9 & 96.3 & 106.5 \\
Patience & 92.5 & 94.6 & 115.7 \\
Importance of proximity to family & 127.4 & 92.4 & 77.2 \\
\hline
\end{tabular}

Note: Columns 2-4 refer to standardised indicators where 'low' ('high') indicates a score of more than one standard deviation below (above) the mean. Sample size varies between 1811 and 1844 across traits

destinations. These graphs can be read like a topographical map: going from brighter to darker areas, the portrayed contours indicate an increasing joint density. The darker the area, the higher the likelihood that study locations in a respective subset feature a specific combination of a place-based characteristic and distance to the average applicant.

As Fig. 3 highlights, locations in the subset of preferred alternatives (left panel) exhibit distinctly higher recreational potential, and thus indicate the relevance of hedonic preferences within the destination choice process. Preferred study locations are concentrated around a share of recreational area on the district level of 3.5\% and an average distance of 170 kilometres. For destinations not in the subset of preferred locations (right panel), a first cluster surfaces in the vicinity of $1.5 \%$ recreational area and 200 kilometres distance and a second at 400 kilometres distance, indicating higher potential costs of migration.

There is also evidence that the analysed young academics did not lose track of future labour market perspectives. Their initial application set tended to include those destinations with higher employment levels for high-skilled workers, measured by the proportion of workers with university degree (Fig. 4). Although both subsets feature 'peaks' for a distance of around $200 \mathrm{~km}$, destinations in the subset of preferred locations (left panel) exhibit a share of high-skilled employment of $13.5 \%$ whereas this share amounts to $9 \%$ for locations in the subset of not preferred alternatives (right panel).

The descriptive analyses in the "Microdata on decision-makers and their university choice sets" and "Characteristics of study location alternatives" sections accentuated choice patterns which are not only related to destination-specific features but also affected by individual personality profiles. Prospective academics seem to sort into locations not only based on expected future returns, as indicated for instance by labour market related preferences, but also based on heterogeneous personality characteristics and (hedonic) preferences. The interaction of individual and destination-specific features, yielding a form of behavioural sorting, will thus be further addressed in a framework acknowledging the existence of heterogeneous agents.

\section{Heterogeneous Agents in a Random Utility Framework}

This research draws upon the random utility model (RUM) and its econometric counterpart, the conditional logit model, which offers some important advantages for this application. First of all, a conditional logit model does not require to specify nests of alternatives, which might be irrelevant from an individual's perspective, as a nested logit model warrants. Second, in contrast to mixed logit models, the focus does not rest on abstract 

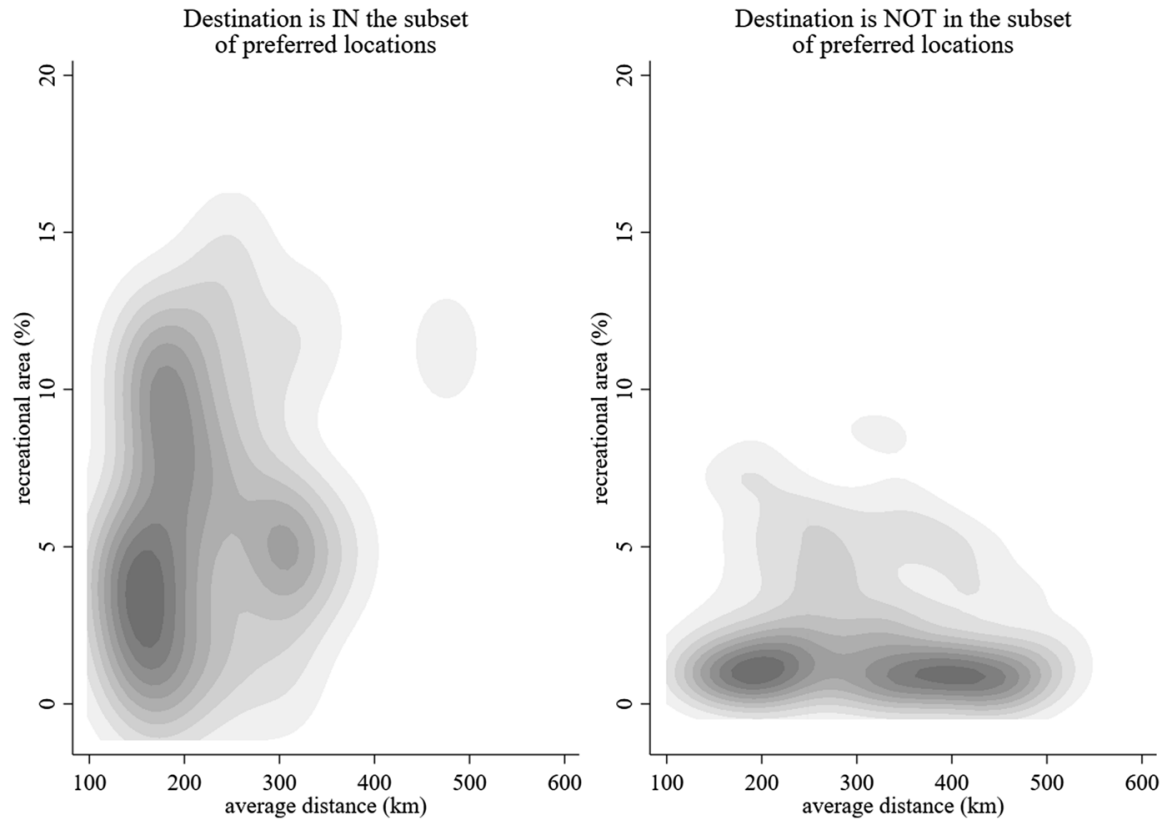

Fig. 3 Bivariate kernel density - destinations' recreational area and distance
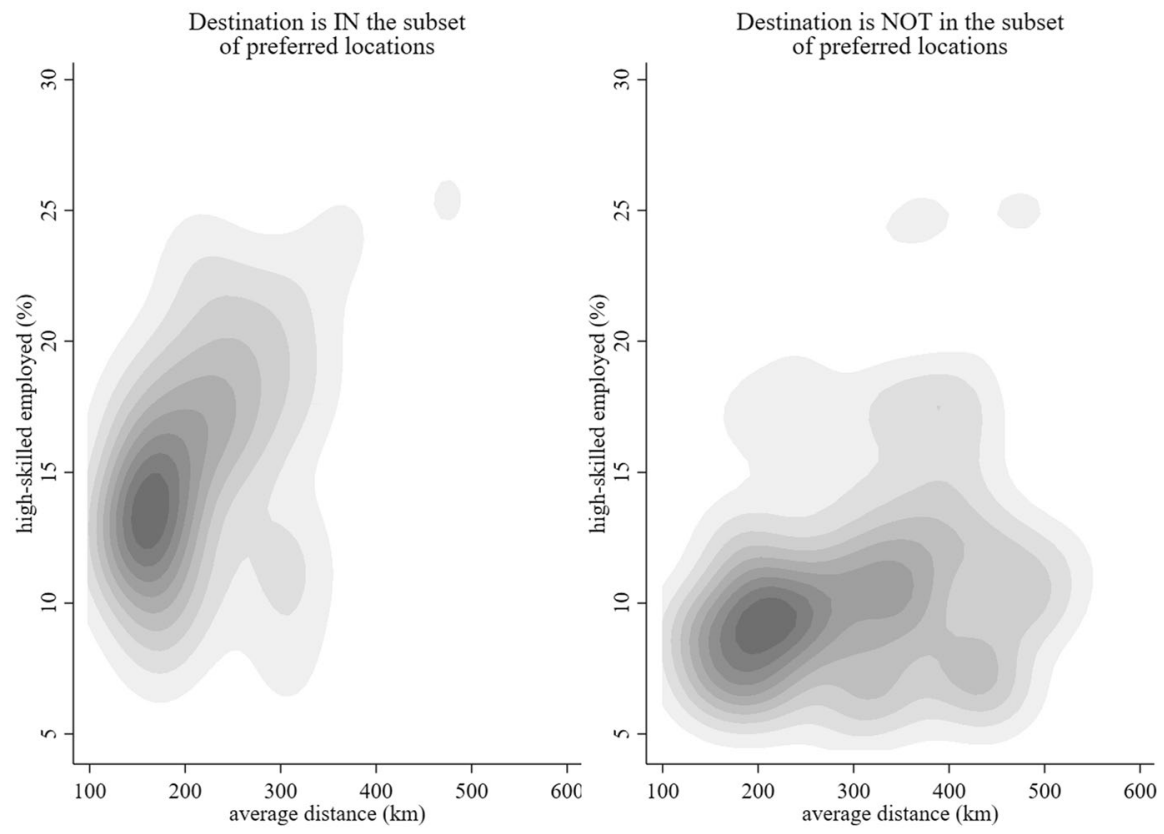

Fig. 4 Bivariate kernel density - destinations' high-skilled employment and distance 
distributions of individual characteristics, but on the impact of directly measured personality traits or preferences in the decision-making process.

The chosen approach also relaxes severe computational limitations in a high-dimensional destination and parameter space while, as the literature suggests (cf. Greene and Hensher 2003; Dahlberg and Eklöf 2003; Greene et al. 2006; Murdock 2006; Bekhor and Prashker 2008; Dahl and Sorenson 2010), it is able to produce estimates in a comparable range to more sophisticated models.

\section{A Conditional Logit Model for Heterogeneous Agents}

Individuals are assumed to evaluate a potential location $l$ based on the corresponding utility $U_{i l}$. The decision-making process of individual $i$ can then be represented by a random utility model (McFadden 1973). Within the university choice context, a study location $l$ is chosen if

$$
U_{i l}>U_{i j} \text { for all other } j \neq l \text { and } j \in D \text { or } U_{i l} \geq U_{i}^{*} .
$$

The first case represents the final enrolment choice among all considered alternatives in an unrestricted destination space $D$. Mirroring the application stage, the second case accommodates choices yielding a set containing several alternatives, which are preferred over the remaining alternatives.

Assuming location-specific utility is linear in parameters (comprised in vector $\omega$ ) relating to a vector $z_{i l}$ of explanatory variables, the probability that study location $l$ is selected can be represented as

$$
P\left(l \mid z_{i l}\right)=P\left[z_{i l}^{\prime} \omega+\varepsilon_{i l}>z_{i j}^{\prime} \omega+\varepsilon_{i j}, \forall j \in D \mid j \neq l\right] .
$$

If the random error term $\varepsilon$ follows a type 1 extreme value distribution, the conditional logit model then states the probability that alternative $l$ is selected among all $D=164$ possible alternatives as

$$
P\left(l \mid z_{i l}\right)=\frac{\exp \left(z_{i l}^{\prime} \omega\right)}{\sum_{l=1}^{D} \exp \left(z_{i l}^{\prime} \omega\right)} .
$$

Heterogeneous agents, varying in their personality and preferences, are introduced by interacting individual characteristics with location-specific attributes. This interaction is required in order to identify parameter estimates related to individual characteristics, which are constant across all alternatives.

Combining these interactions in the matrix vector product $\left[V_{i} X_{i l}\right]^{\prime}$, Eq. 2 can be rearranged into

$$
P\left(l \mid z_{i l}\right)=\frac{\exp \left(x_{i l}^{\prime} \beta+\left[V_{i} X_{i l}\right]^{\prime} \gamma\right)}{\sum_{l=1}^{D} \exp \left(x_{i l}^{\prime} \beta+\left[V_{i} X_{i l}\right]^{\prime} \gamma\right)} .
$$

The joint impact of individual traits $v_{i}$ and location-specific variables $x_{i l}$ may be retrieved in the coefficient vector $\gamma$ (cf. Liaw 1990; Elgar et al. 2015). Coefficients in this vector allow to infer whether different types of individuals display diverging elasticities 
with respect to certain destination-specific conditions. Conveniently, coefficients of interactions between individual traits and distance can be interpreted as measures of heterogeneous costs of migration, i.e. as psychic costs (Sjaastad 1962; Schwartz 1973).

\section{Study Location Choices in a Competing Destinations Framework}

Conditional logit models entail a specific drawback, namely the independence from irrelevant alternatives (IIA) assumption (McFadden 1973). ${ }^{16}$ In general, this assumption follows from Eq. 2 and reads as

$$
\frac{P\left(l \mid z_{i l}\right)}{P\left(j \mid z_{i j}\right)}=\frac{\exp \left(z_{i l}^{\prime} \omega\right)}{\sum_{l=1}^{D} \exp \left(z_{i l}^{\prime} \omega\right)}\left(\frac{\exp \left(z_{i j}^{\prime} \omega\right)}{\sum_{j=1}^{D} \exp \left(z_{i j}^{\prime} \omega\right)}\right)^{-1}=\frac{\exp \left(z_{i l}^{\prime} \omega\right)}{\exp \left(z_{i j}^{\prime} \omega\right)} .
$$

Irrespective whether one or several alternatives (other than $l$ and $j$ ) are added or removed from a choice set, the ratio of these two alternatives' selection probability remains unchanged. In reality, however, this can be violated whenever a newly included alternative is a very close substitute to an existing one (Train 2009).

While alternative study locations might be perceived to be relative close substitutes at a preceding stage, i.e. choosing whether to study or not, this paper's premise is different. In case of individuals who selected themselves into tertiary education, the relevant choice (where to study) is based on a choice set comprising rather distinct alternatives: University cities in Germany display a high degree of variation regarding location-specific characteristics $\left(x_{l}\right)$, e.g. with respect to city size, labour market conditions or price levels (cf. Fig. A.1). Irrespective of this general argument, it cannot be ruled out that a substantial share of prospective academics considers a subset of potential destinations as close substitutes. As a consequence, substitution patterns would no longer be proportional and the IIA violated.

One way to account for critical substitution patterns in spatial choice frameworks is the application of a competing destinations framework (Fotheringham 1983, 1986). Within this framework, a respective alternative's utility is weighted by an accessibility measure $A_{l}$, which is a function of proximity to other alternatives and familiarity, the latter being driven by population size. ${ }^{17}$

This measure (cf. Pellegrini and Fotheringham 2002) integrates two dimensions: one is mental accessibility, related to awareness, and the other refers to physical accessibility (Pramono and Oppewal 2012). This implicit modelling approach also corresponds to a special case of the 'availability/perception' approach of Cascetta and Papola (2001) where alternatives may enter utility based on their likelihood to be element of the resulting 'fuzzy' choice set, i.e. a non-deterministic consideration set: random utility is thus related to alternatives' varying degrees to be perceived or available. ${ }^{18}$

\footnotetext{
16 The IIA can be relaxed using nested logit models (though it can still be an issue within nests) or mixed logit models, which account for individual taste variation but not for a specific taste or personality grouping.

17 The accessibility measure is constructed as $A_{l}\left(D, x_{l}\right)^{\theta}=\left[\frac{1}{D-1} \sum_{j=1, j \neq l}^{D} \frac{p o p_{j}}{d_{l j}}\right]^{\theta}$.

18 The aspect of destination awareness is especially relevant in the context of college choice. For instance, high achieving students in the two top deciles are aware of a larger number of potential college locations (Niu and Tienda 2008).
} 
In the end, the proposed reweighting has interesting implications regarding the independence from irrelevant alternatives (IIA) in a spatial conditional logit model: evaluating location choices in a competing destinations model has an increasing chance that the IIA is not violated, since it only requires to hold that

$$
\frac{P\left(l \mid z_{i l}\right)}{P\left(j \mid z_{i j}\right)}=\frac{\exp \left(z_{i l}^{\prime} \omega\right) A_{l}^{\theta}}{\exp \left(z_{i j}^{\prime} \omega\right) A_{j}^{\theta}}=\frac{\exp \left(z_{i l}^{\prime} \omega+\theta \ln A_{l}\right)}{\exp \left(z_{i j}^{\prime} \omega+\theta \ln A_{j}\right)} .
$$

In this form, adding or removing an alternative with distinct characteristics will modify the accessibility measure $A_{l}$, and consequently change the ratio $A_{l}^{\theta} / A_{j}^{\theta}$. This adjustment, in turn, bears the potential to accommodate observed changes in the relative selection likelihood of two alternatives $l$ and $j$.

\section{Empirical Results}

Based on the conditional logit model for heterogeneous agents, the subsequent section presents baseline estimation results for the corresponding empirical specifications. A more detailed discussion of location choices of heterogeneous decision-makers and resulting sorting patterns takes place in the "Sorting patterns of prospective academics" section. I perform further robustness checks and investigate potential violations of the IIA in the "Robustness checks" section.

Using maximum likelihood estimation, subsequently discussed results originate from conditional logit models where the study location selection likelihood $P\left(l \mid z_{i l}\right)$, as described in Eq. 3, depends on the following linear combination of location and individual specific explanatory variables:

$$
z_{i l}^{\prime} \omega=\beta_{0}+\beta_{d} x_{i l}+\sum \beta_{l} x_{l}+\sum \gamma_{s o c} x_{i l} \times v_{i, s o c}+\sum \gamma_{m o b} x_{i l} \times v_{i, m o b}+\sum \gamma_{p} x_{i l} \times I\left(v_{i, p}\right) .
$$

The set of location specific variables $\left(x_{l}\right)$ comprises economic conditions at the district level (e.g. GDP per capita and various labour market measures) and amenity proxies. Distance to a potential destination $\left(x_{i l}\right)$ enters also interacted with individual-specific variables $v_{i}$. In addition to socio-demographic characteristics $\left(v_{i, s o c}\right)$, previous mobility experiences $\left(v_{i, m o b}\right)$ are accounted for as well.

To assess heterogeneous psychic costs, personality-related variables and preferences $\left(v_{i, p}\right)$ enter the model in categorical form, indicated by the notation $I($.$) . The underlying$ scale variables have been standardised to obtain three distinct groups: the reference group of average type individuals, and two groups scoring at least one standard deviation above (high) or below (low) the mean. The descriptive statistics of all explanatory variables are documented in Table A.1 (in the electronic supplementary material).

\section{The Sensitivity of Estimation Results Regarding Observed Information Sets}

Subsequently discussed estimation results originate from conditional logit models, which vary with respect to the underlying observed information sets, i.e. how many location choices are observed. The two examined information sets correspond to the main stages of the decision-making process (application and enrolment stage). The first model in Table 2 
refers to general study location preferences (preferences in $D$ ), explaining the selection of the three most preferred alternatives at the application stage and the final outcome in the full set of all $D$ potential alternatives. Corresponding to the enrolment stage, the second model (choice in $D$ ) evaluates exclusively the finally observed study location choice in the context of the same destination space.

In general, the results from the two models investigating application preferences and enrolment choice in the complete destination space $(D=164)$ display a high degree of congruence. Typically, if one model attributes a factor explanatory power, the other does too. At the same time, coefficient estimates are slightly larger in absolute size for 'choice in $D$ ', producing odds ratios that are more different from one. ${ }^{19}$

There is also evidence that some factors may play a role of varying importance within the process of selecting a study location. During the application process, individuals have a certain tendency to apply for institutions at locations characterised by lower GDP per capita and higher price levels. If students make their final enrolment choice, they are more likely to choose a destination offering better income perspectives and lower price levels, a hint towards the impact of budget restrictions.

In addition, importance of proximity to friends seems to affect only the choice where to apply, but not where to enrol eventually. A similar observation can be made in case of individuals whose parents have an academic background as well. Beyond that, there is some evidence in favour of ability-related sorting at the enrolment stage. Individuals with weaker scholastic performance, reflected in the UEC grade, display higher odds of selecting themselves into a more distant location. ${ }^{20}$

\section{Sorting Patterns of Prospective Academics}

In order to understand the relevance of heterogeneous preferences and personality characteristics for observed sorting patterns, I estimate a more refined version of the previously described model. ${ }^{21}$ To determine the most appropriate model, I run several model specification tests. Integrating further interactions of selected personality traits and economic conditions yielded the highest model fit (Table A.4 in the electronic supplementary material).

This model of enrolment choice (Table A.5 in the electronic supplementary material) acknowledges that individuals of different risk attitude or time preferences might display distinct geographic sorting patterns: less patient workers might exert less effort in the job search (DellaVigna and Paserman 2005), i.e. less patient prospective academics might not consider future job perspectives at the stage of study location choice. On the other hand, a lower degree of risk aversion in the labour force is related to higher levels of

\footnotetext{
19 Odds ratios indicate by how much the odds of one alternative to be chosen increase (decrease) if an explanatory variable changes by one unit. Referring to 'choice in $D$ ' (Table 2), for example, if two alternatives at 100 and 101 kilometres distance are compared (and everything else is held constant), the odds that the second alternative is chosen are 0.9695 times the odds that the closer alternative is selected.

${ }^{20}$ UEC (university entrance certificate) grades in Germany, required to be formally entitled to apply at universities, are on a scale from 1 to 4 (1 indicates highest scholastic achievement, 4 refers to the passing grade).

21 In view of the high degree of congruence between the models related to differing information sets (cf. "The sensitivity of estimation results regarding observed information sets" section) the subsequent focus on the observed enrolment choice seems justifiable.
} 
Table 2 Conditional logit models for varying information sets

\begin{tabular}{|c|c|c|}
\hline Dependent variable & Preferences in $D$ & Choice in $D$ \\
\hline Observed location choices & $S \leq 4$ & $S=1$ \\
\hline \multirow[t]{2}{*}{ Destination space } & $D=164$ & $D=164$ \\
\hline & OR (SE) & OR (SE) \\
\hline \multicolumn{3}{|l|}{$x_{i l}$} \\
\hline Distance & $0.9830 * * *(0.0043)$ & $0.9695 * * *(0.0060)$ \\
\hline \multicolumn{3}{|l|}{$x_{l}$} \\
\hline Population & $1.0015 * * *(0.0001)$ & $1.0025 * * *(0.0001)$ \\
\hline Population density & $0.9986^{* * *}(0.0001)$ & $0.9961 * * *(0.0001)$ \\
\hline GDP (per capita) & $0.9939 * * *(0.0018)$ & $1.0138 * * *(0.0019)$ \\
\hline Price level $\left(€ / \mathrm{m}^{2}\right)$ & $1.0013 * * *(0.0002)$ & $0.9971 * * *(0.0003)$ \\
\hline Share of recreational area & $1.1764 * * *(0.0115)$ & $1.3074 * * *(0.0183)$ \\
\hline Reg. centre reachability & $0.9505 * * *(0.0021)$ & $0.9187 * * *(0.0044)$ \\
\hline Unemployment rate & $1.1563^{* * *}(0.0205)$ & $1.0542 *(0.0304)$ \\
\hline Youth unemp. rate & $0.9919(0.0175)$ & $1.7445 * * *(0.0590)$ \\
\hline High-skilled emp. rate & $0.9340 * * *(0.0070)$ & $0.8468 * * *(0.0147)$ \\
\hline High-skilled emp. rate $(<34)$ & $1.0773 * * *(0.0030)$ & $1.1785 * * *(0.0070)$ \\
\hline \multicolumn{3}{|l|}{$v_{i} \times x_{i l}$} \\
\hline Female & $0.9990(0.0007)$ & $0.9992(0.0009)$ \\
\hline Age & $1.0002(0.0002)$ & $0.9998(0.0003)$ \\
\hline UEC grade & $0.9994(0.0006)$ & $1.0054 * * *(0.0009)$ \\
\hline Academic household & $1.0023 * * *(0.0006)$ & $1.0011(0.0009)$ \\
\hline In partnership & $0.9981 * * *(0.0007)$ & $0.9979 * *(0.0009)$ \\
\hline Vocational education & $0.9991(0.0012)$ & $0.9966 * *(0.0016)$ \\
\hline Moved during school & $1.0015^{* *}(0.0007)$ & $1.0018^{*}(0.0010)$ \\
\hline Exchange participation & $1.0026^{* * *}(0.0007)$ & $1.0028 * * *(0.0009)$ \\
\hline Stay abroad & $1.0045 * * *(0.0007)$ & $1.0049 * * *(0.0009)$ \\
\hline \multicolumn{3}{|l|}{ Risk attitude } \\
\hline Low & $0.9982 * *(0.0007)$ & $0.9982 *(0.0011)$ \\
\hline High & $0.9999(0.0010)$ & $1.0011(0.0013)$ \\
\hline \multicolumn{3}{|l|}{ Patience } \\
\hline Low & $0.9982 *(0.0010)$ & $0.9989(0.0012)$ \\
\hline High & $1.0018 * *(0.0008)$ & $1.0023 * *(0.0011)$ \\
\hline \multicolumn{3}{|l|}{ Extraversion } \\
\hline Low & $0.9989(0.0011)$ & $0.9995(0.0015)$ \\
\hline High & $0.9990(0.0008)$ & $0.9990(0.0010)$ \\
\hline \multicolumn{3}{|l|}{ Openness } \\
\hline Low & $0.9986(0.0009)$ & $0.9981(0.0011)$ \\
\hline High & $1.0017 * *(0.0008)$ & $1.0014(0.0011)$ \\
\hline \multicolumn{3}{|l|}{ Neuroticism } \\
\hline Low & $0.9988(0.0010)$ & $0.9978(0.0014)$ \\
\hline High & $1.0012(0.0009)$ & $0.9998(0.0013)$ \\
\hline \multicolumn{3}{|l|}{ Conscientiousness } \\
\hline Low & $0.9997(0.0008)$ & $1.0002(0.0010)$ \\
\hline High & $0.9989(0.0008)$ & $0.9981(0.0013)$ \\
\hline
\end{tabular}


Table 2 (continued)

\begin{tabular}{lll}
\hline Dependent variable & Preferences in $D$ & Choice in $D$ \\
Observed location choices & $S \leq 4$ & $S=1$ \\
Destination space & $D=164$ & $D=164$ \\
& OR (SE) & OR (SE) \\
\hline Agreeableness & & \\
Low & $0.9988(0.0009)$ & $0.9981^{*}(0.0011)$ \\
High & $0.9999(0.0008)$ & $1.0016(0.0011)$ \\
Adaptability & & $0.9979 *(0.0012)$ \\
Low & $0.9984^{*}(0.0009)$ & $1.0036^{* * *}(0.0011)$ \\
High & $1.0025^{* * *}(0.0009)$ & \\
Importance of proximity to family & & $1.0031^{* * *}(0.0012)$ \\
Low & $1.0020^{* *}(0.0008)$ & $0.9993(0.0015)$ \\
High & $0.9985(0.0011)$ & $1.0020(0.0013)$ \\
Importance of proximity to friends & & $0.9998(0.0016)$ \\
Low & $1.0020^{* *}(0.0009)$ & $1712 \times D$ \\
High & $0.9981(0.0012)$ & 6793.91 \\
Observations & $1712 \times D$ & 0.0000 \\
Wald $\chi^{2}$ & 6624.60 & 0.5286 \\
Prob $>\chi^{2}$ & 0.0000 & 0.3731 \\
Pseudo R-squared & & \\
\hline
\end{tabular}

Note: A sequential model comparison for 'preferences in $D$ ' and 'choice in $D$ ' is performed in Table A.2 and Table A.3 (in the electronic supplementary material). Standard errors are clustered at the individual level. ' $X$ ' indicates interactions between distance and individual-specific characteristics

$* * * p<0.01, * * p<0.05, * p<0.1$

unemployment (Pissarides 1974), implying a more developed tolerance for being unemployed of more risk-loving individuals.

The odds ratios from the refined model confirm the results from the baseline model. We observe again the distance deterrence effect and that individuals tend to sort into destinations with a larger population, which are at the same time not too densely populated. There is also a tendency to select locations potentially offering higher consumption levels, since districts with higher GDP per capita or lower price levels are more likely to be chosen. While a larger share of recreational space seems to serve as attractor, higher travel time to the next regional centre works in the opposite direction, as an odds ratio below one for 'regional centre reachability' (measured in minutes) indicates.

The interaction terms between distance and individual characteristics provide the following interpretations: Individuals with previous mobility experience, e.g. a move during childhood or episodes abroad, display odds ratios above one. They are more willing to choose a study location farther away, since these previous experiences mitigate the perceived costs of mobility. Something similar can be observed for those expressing a relatively low preference for proximity to their family. The inversion of the argument, however, implies that more family-oriented prospective academics face higher psychic costs and have a limited destination space, and hence fewer institutions to choose amongst. 
Regarding the impact of personality traits, the classical Big-Five personality traits (openness, conscientiousness, extraversion, agreeableness and neuroticism) do not yield robust results. Any conclusion that personality characteristics do not matter would be premature: those with the lowest willingness to take risks (compared to those of average risk attitude) are distinctly less likely to sort themselves into a destination at a certain distance to their origin.

As hypothesised, individual patience, measured as willingness to bear costs in the present for the sake of future rewards, is an important and highly robust factor: Least patient prospective academics seem to be less likely to select a study location further away. Consistently, most patient individuals are characterised by a notably larger potential willingness to display mobility for educational purposes. For them, increasing returns to tertiary education - by enlarging the choice set of suitable institutions - is especially rewarding.

Another relevant factor, attenuating the more immediate psychic costs of integrating into a new social and urban environment, is the ability to adjust to new circumstances. Those expressing highest (lowest) levels of adaptability have higher (lower) odds of picking an alternative at a certain distance than the reference group.

In order to provide a more immediate interpretation of the interaction effects of distance and location-specific conditions, on the one hand, and individual traits, on the other, Figs. 5, 6, 7, 8 and 9 document selected relations. Included average marginal effects (AME) and predicted choice probabilities are derived within the area of support of distance, i.e. for distances in the range of $0-600 \mathrm{~km} .^{22}$

Figure 5 illustrates a diminishing distance deterrence effect for any destinations further away than $100 \mathrm{~km}$. Comparing two alternatives, one in $200 \mathrm{~km}$ distance and the other (probably in another direction) $201 \mathrm{~km}$ away, the selection probability decreases on average by $0.2 \%$ points. For two locations in the vicinity of $300 \mathrm{~km}$ distance, this effect is only half as large. This attenuating distance deterrence effect is known from the literature (Long 2004).

Figure 6 demonstrates that the distance deterrence effect is, in fact, related to individual characteristics. The non-overlapping confidence intervals for larger distances point to a distinct difference between individuals who have a previous mobility experience abroad and those who do not (left panel): For instance, those having spent time abroad are twice as likely to enrol at a university in $300 \mathrm{~km}$ distance compared to those who lack such an experience. The same holds for those with a high adaptability to new circumstances in contrast to those facing a harder time in a new living environment (right panel). The effect on the selection likelihood of a potential destination is rather strong: whereas most adaptable individuals feature a $20 \%$ probability of choosing a location in $300 \mathrm{~km}$ distance, least adaptable individuals do so with a probability of only $10 \%$.

Turning to some pivotal urban statistics, namely population size and density, gross domestic product (GDP) per capita and price levels (measured as building plot prices), observed average marginal effects are significant for all potential national destinations in a distance of up to $600 \mathrm{~km}$ (Fig. 7, left panel).

Although many universities are situated in larger cities, negative average marginal effects of population density and price levels indicate that beginning students have a certain preference for less crowded and more affordable destinations. Prospective academics

\footnotetext{
${ }^{22}$ This range covers $99 \%$ of all potential paths for each of the 1712 individuals in the sample to any of the 164 potential destinations.
} 
Fig. 5 The decay of the distance deterrence effect. Note: The whiskers indicate the $90 \%$ confidence interval

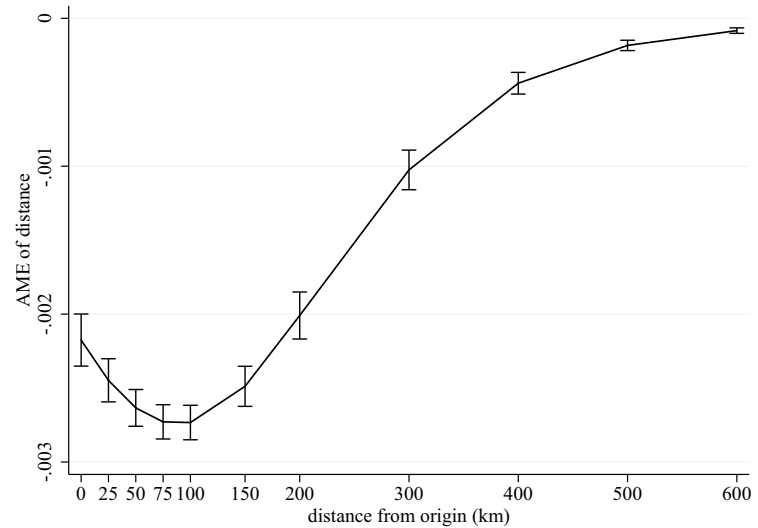

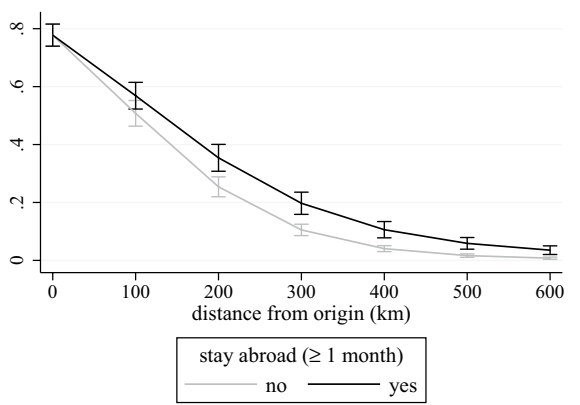

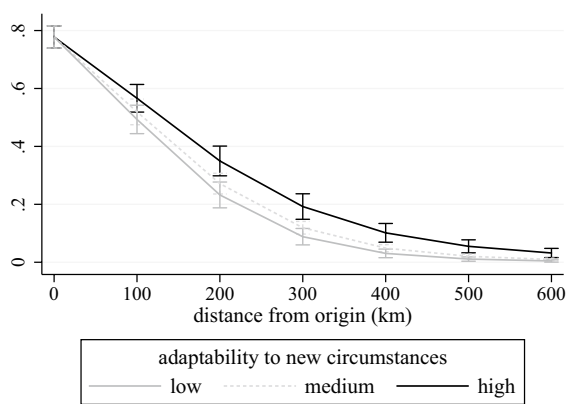

Fig. 6 Predicted destination selection likelihood, by various individual characteristics. Note: Left axes represent an alternative's predicted selection likelihood. The whiskers indicate the $90 \%$ confidence interval

in the sample also exhibit a preference for destinations with higher GDP per capita, yet the interest in destinations offering higher wealth levels diminishes in distance.

The right panel in Fig. 7 graphs average marginal effects for the share of recreational area and reachability of the closest regional centre. Both can be interpreted as factors contributing to quality of life. The first referring to a more hedonistic concept of well-being and the latter is a proxy for access to a variety of amenities which cannot be found in smaller cities (larger shopping malls, theatres or the like). Longer travel times to metropolitan centres, implying lower levels of accessibility to urban amenities, are associated with a smaller destination selection likelihood. The relative impact of recreational potential is strong: If the share of the recreational area at a destination in $100 \mathrm{~km}$ distance was to increase by one percentage point, destination selection likelihood would increase by more than $3 \%$ points.

The relevance of the hedonic concept can be further disentangled (Fig. 8). Average marginal effects across the group of those who spent time abroad and those who never made such a previous mobility experience differ notably. If recreational area was to increase by one percentage point for a destination in $300 \mathrm{~km}$ distance, selection likelihood increases on average by more than $2 \%$ points for those who displayed this type of previous cross-border 

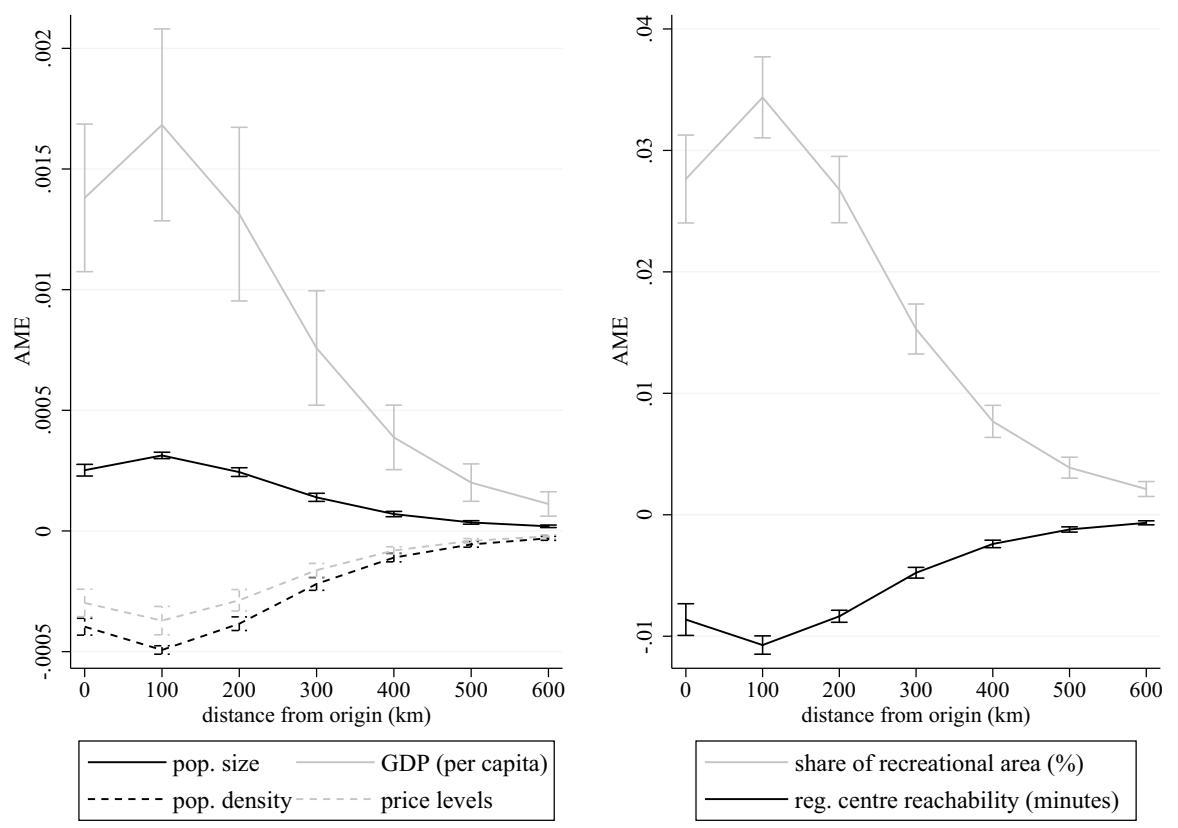

Fig. 7 Average marginal effects (AME) of various urban characteristics over distance. Note: The whiskers indicate the $90 \%$ confidence interval

Fig. 8 Average marginal effect (AME) of recreational value, by distance and previous cross-border mobility. Note: The whiskers indicate the $90 \%$ confidence interval

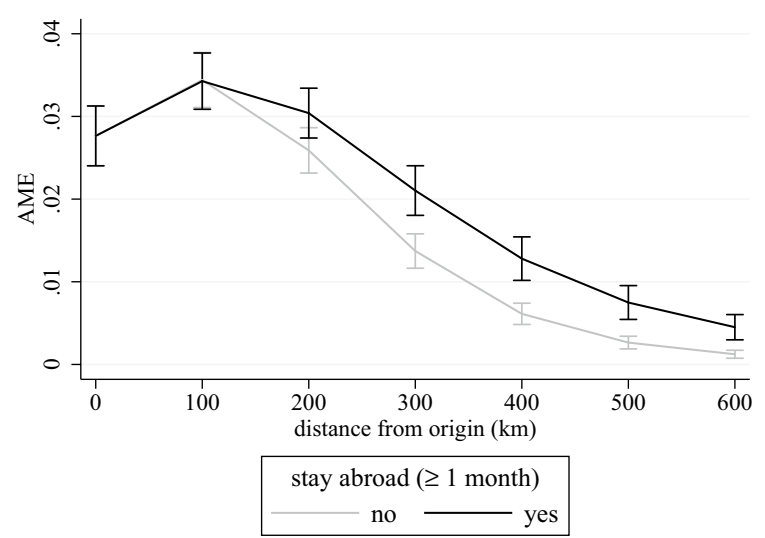

mobility. For individuals who did not make such an experience yet, the likelihood increases on average only by approximately $1.4 \%$ points.

Individual-specific characteristics exert heterogeneous effects on study location choices also in the context of labour market related aspects. Especially levels of patience, corresponding to various degrees of time preferences, prove insightful (Fig. 9). The upper left panel illustrates average marginal effects for the high-skilled employment rate at a destination, the upper right panel the corresponding graphs for the young high-skilled employment rate. The latter informs about the current job perspectives for university graduates in the age bracket of 30-34 years. 


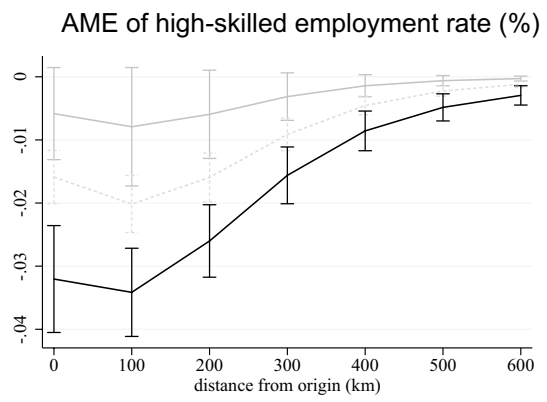

AME of young high-skilled employment rate (\%o)

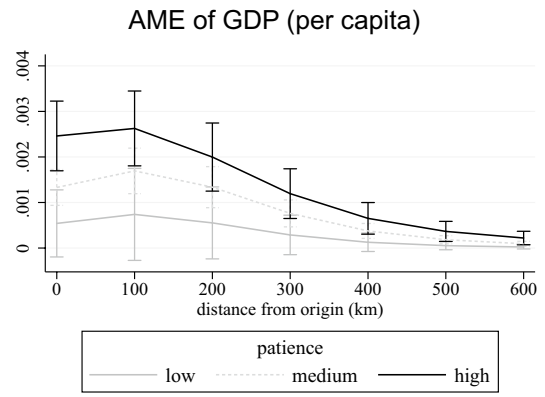

Fig. 9 Average marginal effects (AME) for labour market characteristics. Note: The whiskers indicate the $90 \%$ confidence interval

Least patient individuals display no sensitivity with respect to the age independent highskilled employment rate ( $90 \%$ confidence interval includes zero). Most patient individuals, in turn, are much less likely to choose a location with good job prospects for academics. This result is only a conundrum at first glance, since most patient individuals are much more likely to select themselves into a destination with higher employment rates of academics in their early thirties. Ultimately, these most patient individuals have a strong preference for destinations which labour markets are characterised by two features: good job perspectives for young academics who just established themselves in the labour market, on the one hand, and a not overly fierce competitive situation with older (more experienced) workers, on the other.

The lower panel in Fig. 9 reports the average marginal effect of GDP per capita, which can also be interpreted as proxy for expected income. Once again, least patient individuals do not show any significant sensitivity with respect to higher income levels. Thus, the observed relevance of higher potential GDP per capita levels (Fig. 7) is mainly attributable to the most patient individuals.

The results highlighted in Fig. 9 insinuate that the choice of a study location might indeed already inform about subsequent location choices (cf. Belfield and Morris 1999; Groen 2004; Busch and Weigert 2010; Buenstorf et al. 2016). This also confirms the general findings of McHugh and Morgan (1984) and Dotti et al. (2013), who elaborated that economic conditions matter already at such a pre-labour market entry stage.

My results provide a refined behavioural explanation and reveal why some previous studies (e.g. Gibbons and Vignoles 2012) failed to detect a significant interrelation between labour market characteristics and university choices: The aggregate perspective, allowing solely for socio-economic or socio-demographic heterogeneity, masques substantial heterogeneity in personality. In reality, however, different types of individuals exhibit rather 
distinct valuations of place-based characteristics, such as economic conditions or amenities. In this regard, it is especially the most patient individuals who make in the present such distinct location choices while keeping local post-graduation employment prospects, the future returns, in mind. Yet, even for the most patient and considerate decision-makers, distance-dependent costs of mobility restrict the set of potential study locations.

\section{Robustness Checks}

Results in a discrete choice model depend crucially on the definition of the underlying choice set, i.e. which alternatives decision-makers were choosing from. In case of choice set misspecification, estimated effects of factors influencing location choices might be severely biased (Parsons and Hauber 1998; Hicks and Strand 2000; Elgar et al. 2015). ${ }^{23}$ So far, my definition of the choice set was based on the assumption that all 164 locations offering an economics or business programme are relevant potential destinations.

However, if individuals were to apply elimination by aspects (Tversky 1972) within the choice set formation process, e.g. eliminating universities of applied sciences or alternatives in small cities from their consideration set, the complete destination space would misrepresent their actual choice set and bias estimation results. Acknowledging that the sample consists of students who signalled, by their observed enrolment choice, a certain preference for comprehensive universities, one robustness check addresses the issue of an initial elimination of all universities of applied sciences: The destination space is restricted to include only those destinations hosting a comprehensive university. This reduces the destination space in the initial application process to $D_{U}=71$. In order to further mitigate the problem of choice set misspecification due to the inclusion of institutions no one in the sample was actually aware of, another version of the initial destination space comprises only those destinations $\left(D_{S}=101\right)$ which have been stated as most preferred (or finally chosen) alternatives by at least one individual in the sample. This should increase the likelihood that the modelled destination space represents the actual destination space more precisely.

A comparison of baseline results (Table 2) and those drawing on the restricted destination spaces (Table A.6 in the electronic supplementary material) demonstrates that the estimation results are highly robust with respect to the three alternative destination space definitions. Using the complete destination space $D$, including all destinations hosting any type of university offering an economics or business programme, does not adversely affect the results' reliability. ${ }^{24}$

Another robustness check makes allowance for the broad definition of economics and business programmes. Some of these might have a more specific focus and are not necessarily offered with the desired curriculum at all institutions included in the destination space. ${ }^{25}$ If someone is interested in International Management, institutions and therefore

\footnotetext{
${ }^{23}$ I also investigated the aspect of choice set definition and various forms of misspecifications in a simulation study. Results are available upon request.

24 The same conclusion applies when this robustness check is applied to the richer model of the "Sorting patterns of prospective academics" section (cf. Table A.5, columns 3 and 4 in the electronic supplementary material).

25 Within the sample, programme features have been mentioned by $75.6 \%$ as an important aspect for their final choice. Other potentially relevant aspects, which might have been applied in a preceding unobserved elimination by aspects choice set formation process, are 'proximity to the origin' and 'interest in the city'. These aspects are directly incorporated into the model, e.g. by using distance and various city-related indicators.
} 
destinations offering only Business Studies are probably no valid alternatives and would have been eliminated from this individual's choice set. High degrees of programme similarity, in turn, can be attributed to programmes labelled Business Studies and Economics and Business. At least one of these programmes is offered at those destinations, spanning the complete destination space. These are also the most frequently chosen programmes in the sample and in the population of freshmen in 2013 (Destatis 2014a).

To assess the impact of programme selectivity, the models are re-estimated in a restricted sample comprising only students who enrolled in a Business or Economics and Business programme. The most noteworthy change (Table A.7 in the electronic supplementary material) is due to an increase of the estimates' variance: odds ratios for individuals attributing proximity to family a low importance and those with completed vocational training are only significant in the full sample. Ultimately, restricting the sample to those 1391 individuals enrolled in one of the two programmes preserves the general sorting patterns.

A third robustness check addresses concerns regarding a potential violation of the IIA. Restricting the destination set by excluding one alternative at a time, estimated coefficients can be compared to those obtained from the unrestricted models. Applying the HausmanMcFadden test (Hausman and McFadden 1984), unreported results indicate a certain likelihood that some of the restrictive assumptions of the conditional logit model are not met. Yet, the distribution of estimated coefficients in the 164 restricted samples is highly concentrated around the coefficients in the unrestricted destination space (Table A.8 in the electronic supplementary material). In addition, the obtained estimates are in so far reliable as the number of significant parameter estimates in the restricted samples reveals. Factors that were found to be significant predictors in the unrestricted destination space retain their significant predictive power in the restricted samples.

The final robustness check relaxes the IIA by applying a competing destinations framework (cf. the "Study location choices in a competing destinations framework" section). The estimation outcomes in such a competing destinations framework (Table A.9 in the electronic supplementary material) support previous findings. Nevertheless, varying magnitudes of location-specific conditions' estimates illustrate a certain sensitivity of results with respect to the assumed decision-making process. The overall patterns, however, especially regarding interactions of individual personality-related and alternative-specific characteristics, remain stable in the context of a competing destinations framework, relaxing the IIA. This promotes confidence in the baseline results from the "The sensitivity of estimation results regarding observed information sets" section and the extensions presented in the section on "Sorting patterns of prospective academics".

\section{Conclusion}

This paper analyses study enrolment choices of undergraduate students at German universities in light of their varying preferences and personality characteristics. The main focus of the empirical analysis rests on study location choices of students, who are mostly homogeneous in their study preferences, but heterogeneous with respect to their perception of costs and returns related to migration. The applied empirical framework accounts for discrete location choices in the presence of a plethora of alternative study locations, each offering a distinct combination of economic conditions and urban amenities. The novelty 
of this research comes from illustrating that these location-specific conditions are valued differently across individuals displaying varying types of personality and preferences.

Most patient individuals are more likely to select a location offering better post-graduation employment perspectives for high-skilled workers or higher potential income levels. Yet, the appeal of such labour market conditions diminishes drastically if distance to a potential destination increases. Price levels and population density exert a deterring effect, which is also fading over distance. On the other hand, hedonic motives and access to amenities play an important role. This is especially true for individuals who displayed higher levels of geographic mobility in the past, and thus face in all likelihood lower psychic costs of migration.

The interaction of distance and personality attributes also revealed that the distance deterrence effect is not constant across an otherwise rather homogeneous population of prospective academics: perceived costs of mobility are not evenly increasing in distance, but relative to individual traits and preferences.

My results suggest that universities located in medium sized and well-connected cities benefit from an enlarged pool of applicants. Moreover, students are attracted to study locations which offer relatively higher amenity levels. This points to a clear advantage of institutions in cities offering high living standards and recreational value. In this regard, city attractiveness and prestigious campus buildings could be seen as substitutes-financially constraint universities in amenity-rich cities might emphasise their attractive environment instead of engaging in sumptuous (construction) activities.

From a micro-perspective, my results also feature some direct implications with respect to the composition of universities' applicant pools: More remote universities have a higher likelihood to attract individuals with previous mobility experiences or a higher level of adjustment capability. Both point to an increased capacity to handle challenges arising during studies.

Universities located in economically less advantageous regions might attract a larger share of applicants exhibiting higher levels of impatience. Given the fact that time preferences are directly related to cognitive ability or academic performance (Kirby et al. 2005; Dohmen et al. 2010; Golsteyn et al. 2014; Non and Tempelaar 2016) the observed sorting pattern could translate into a relatively weaker average performance at these institutions. Whereas the causes for such an adverse pooling cannot be directly addressed by a respective university, additional measures to support students' learning success could be implemented. At the same time, and since these external causes will be related to the business cycle, a constant readjustment might be required.

This study, however, has a few limitations which deserve mentioning: The study's focus on a sample of undergraduate students enrolled in one of the most popular groups of programmes might limit its explanatory power when it comes to location choices of post-graduate students or those with study interests in an academic niche. Moreover, the restriction to the Big-Five personality traits might not fully reflect the richness of personality traits established in the psychological literature. Lastly, the case of the German higher education system, in which university rankings tend to play a lesser role, might be considered as a special case.

Although findings from the German higher education system might not be completely transferable to other major higher education markets, there are several aspects which foster the results' relevance: For one, there are no distortions related to tuition fees or university marketing activities. Moreover, the German higher education sector is a mature sector of substantial size. The programme structure follows largely the Anglo-American higher education realm. Acknowledging that there remains a notable 
difference between the US and the German higher education system, a gradually declining sensitivity of college choice regarding tuition fees in the US (Long 2004; Skinner 2019) and a continuously advanced internationalisation of the German higher education landscape imply that some findings could be generalised.

Ultimately, there emerge several avenues for future research which would address some of the above mentioned limitations and foster external validity, e.g. by investigating the interaction of personality and geography in the US higher education market. A further extension of this research could be to examine study location choices of a more general student population. Another promising refinement would be the application of an even broader personality concept or the integration of location choices of unsuccessful applicants. Yet the major obstacle to such a research agenda is the rare joint availability of detailed data on location choice processes and personality traits.

Funding The author did not receive any external funding to conduct this research.

\section{Compliance with Ethical Standards}

Conflict of interest The author declares that he has no conflict of interest.

Data Availability The dataset analysed during the current study is available in the GESIS Data Archive repository, https://doi.org/10.4232/1.12544.

Open Access This article is distributed under the terms of the Creative Commons Attribution 4.0 International License (http://creativecommons.org/licenses/by/4.0/), which permits unrestricted use, distribution, and reproduction in any medium, provided you give appropriate credit to the original author(s) and the source, provide a link to the Creative Commons license, and indicate if changes were made.

\section{References}

Alm, J., \& Winters, J. V. (2009). Distance and intrastate college student migration. Economics of Education Review, 28, 728-738.

Avery C., \& Hoxby, C. M. (2004). Do and should financial aid packages affect students' college choices? In C. M. Hoxby (Ed.), College choices: The economics of where to go, when to go, and how to pay for it. University of Chicago Press.

BBSR. (2014). Indikatoren und Karten zur Raum- und Stadtentwicklung. INKAR. Ausgabe 2014; Bundesinstitut für Bau-, Stadt- und Raumforschung (BBSR) im Bundesamt für Bauwesen und Raumordnung (BBR), Bonn.

Beine, M., Noël, R., \& Ragot, L. (2014). Determinants of the international mobility of students. Economics of Education Review, 41, 40-54.

Bekhor, S., \& Prashker, J. N. (2008). GEV-based destination choice models that account for unobserved similarities among alternatives. Transportation Research Part B, 42, 243-262.

Belfield, C., \& Morris, Z. (1999). Regional migration to and from higher education institutions: Scale, determinants and outcomes. Higher Education Quarterly, 53(3), 240-263.

Brezis, E. S., \& Soueri, A. (2011). Why do students migrate? Where do they migrate to? AlmaLaurea Working Papers, No. 25, September 2011.

Buenstorf, G., Geissler, M., \& Krabel, S. (2016). Locations of labor market entry by German university graduates: Is (regional) beauty in the eye of the beholder? Review of Regional Research, 36, 29-49.

Busch, O., \& Weigert, B. (2010). When have all the graduates gone? Internal cross-state migration of graduates in Germany 1984-2004. The Annals of Regional Science, 44, 559-572.

Canache, D., Hayes, M., Mondak, J. J., \& Wals, S. C. (2013). Openness, extraversion and the intention to emigrate. Journal of Research in Personality, 47, 351-355.

Carson, R. T., \& Louviere, J. J. (2014). Statistical properties of consideration sets. The Journal of Choice Modelling, 13, 37-48. 
Cascetta, E., \& Papola, A. (2001). Random utility models with implicit availability/perception of choice alternatives for the simulation of travel demand. Transportation Research Part C, 9, 249-263.

Clark, D. E., \& Cosgrove, J. C. (1991). Amenities versus labor market opportunities: Choosing the optimal distance to move. Journal of Regional Science, 31(3), 311-328.

Cooke, T. J., \& Boyle, P. (2011). The migration of high school graduates to college. Educational Evaluation and Policy Analysis, 33(2), 202-213.

Dahl, M. S., \& Sorenson, O. (2010). The migration of technical workers. Journal of Urban Economics, 67, $33-45$.

Dahlberg, M., \& Eklöf, M. (2003). Relaxing the IIA assumption in locational choice models: A comparison between conditional logit, mixed logit, and multinomial probit models. Working Paper, Department of Economics, Uppsala University, No. 2003:9.

Davies, P. S., Greenwood, M. J., \& Li, H. (2001). A conditional logit approach to U.S. state-to-state migration. Journal of Regional Science, 41(2), 337-360.

DellaVigna, S., \& Daniele Paserman, M. (2005). Job search and impatience. Journal of Labor Economics, 23(3), 527-588.

Destatis. (2014a). Bildung und Kultur. Studierende an Hochschulen. Wintersemester 2013/14; Statistisches Bundesamt, Wiesbaden, Fachserie 11 Reihe 4.1.

Destatis. (2014b). 2,1\% weniger BAFöG-Empfänger/-innen im Jahr 2013. Press release 283/14, 12/08/2014.

Destatis. (2018). Bildung und Kultur. Studierende an Hochschulen-Vorbericht. Wintersemester 2017/18; Statistisches Bundesamt, Wiesbaden, Fachserie 11 Reihe 4.1.

Dohmen, T., Falk, A., Huffman, D., \& Sunde, U. (2010). Are risk aversion and impatience related to cognitive ability? American Economic Review, 100(3), 1238-1260.

Dotti, N. F., Fratesi, U., Lenzi, C., \& Percoco, M. (2013). Local labour markets and the interregional mobility of Italian university students. Spatial Economic Analysis, 8(4), 443-468.

Drewes, T., \& Michael, C. (2006). How do students choose a university?: An analysis of applications to universities in Ontario, Canada. Research in Higher Education, 47(7), 781-800.

Elgar, I., Farooq, B., \& Miller, E. J. (2015). Simulations of firm location decisions: Replicating office location choices in the Greater Toronto Area. The Journal of Choice Modelling, 17, 39-51.

Faggian, A., \& McCann, P. (2006). Human capital flows and regional knowledge assets: A simultaneous equation approach. Oxford Economic Papers, 52, 475-500.

Faggian, A., McCann, P., \& Sheppard, S. (2007). Some evidence that women are more mobile than men: Gender differences in U.K. graduate migration behavior. Journal of Regional Science, 47(3), 517-539.

Fotheringham, A. S. (1983). Some theoretical aspects of destination choice and their relevance to productionconstrained gravity models. Environment and Planning A, 15(8), 1121-1132.

Fotheringham, A. S. (1986). Modelling hierarchical destination choice. Environment and Planning A, 18, $401-418$.

Gibbons, S., \& Vignoles, A. (2012). Geography, choice and participation in higher education in England. Regional Science and Urban Economics, 42, 98-113.

Golsteyn, B. H. H., Grönqvist, H., \& Lindahl, L. (2014). Adolescent time preferences predict lifetime outcomes. The Economic Journal, 124, 739-761.

Greene, W. H., \& Hensher, D. A. (2003). A latent class model for discrete choice analysis: Contrasts with mixed logit. Transportation Research Part B, 37, 681-698.

Greene, W. H., Hensher, D. A., \& Rose, J. (2006). Accounting for heterogeneity in the variance of unobserved effects in mixed logit models. Transportation Research Part B, 40, 75-92.

Groen, J. A. (2004). The effect of college location on migration of college-educated labor. Journal of Econometrics, $121,125-142$.

Hausman, J., \& McFadden, D. (1984). Specification tests for the multinomial logit model. Econometrica, 52(5), 1219-1240.

Hicks, R. L., \& Strand, I. E. (2000). The extent of information: Its relevance for random utility models. Land Economics, 79(3), 374-385.

Hillman, N. W. (2016). Geography of college opportunity: The case of education deserts. American Educational Research Journal, 53(4), 987-1021.

HRK. (2015). Hochschulkompass; Stiftung zur Förderung der Hochschulrektorenkonferenz (ed.). www.hochs chulkompass.de. Accessed 14 April 2015.

Jaeger, D. A., Dohmen, T., Falk, A., Huffman, D., Sunde, U., \& Bonin, H. (2010). Direct evidence on risk attitudes and migration. The Review of Economics and Statistics, 92(3), 684-689.

Jepsen, C., \& Montgomery, M. (2009). Miles to go before I learn: The effect of travel distance on the mature person's choice of a community college. Journal of Urban Economics, 65, 64-73.

Jokela, M. (2009). Personality predicts migration within and between U.S. states. Journal of Research in Personality, 43, 79-83. 
Kirby, K. N., Winston, G. C., \& Santiesteban, M. (2005). Impatience and grades: Delay-discount rates correlate negatively with college GPA. Learning and Individual Differences, 15(3), 213-222.

Kohn, M. G., Manski, C. F., \& Mundel, D. D. S. (1976). An empirical investigation of factors which influence college-going behavior. Annals of Economic and Social Measurement, 5(4), 391-419.

Leppel, K. (1993). Logit estimation of a gravity model of the college enrollment decision. Research in Higher Education, 34(3), 387-398.

Liaw, K.-L. (1990). Joint effects of personal factors and ecological variables on the interprovincial migration patterns of young adults in Canada: A nested logit analysis. Geographical Analysis, 22(3), 189-208.

Long, B. T. (2004). How have college decisions changed over time? An application of the conditional logistic choice model. Journal of Econometrics, 121, 271-296.

McCrae, R. R., \& Costa Jr., P. T. (2004). A contemplated revision of the NEO Five-Factor Inventory. Personality and Individual Differences, 36, 587-596.

McFadden, D. L. (1973). Conditional logit analysis of qualitative choice behavior. In P. Zarembka (Ed.), Frontiers in econometrics (pp. 105-142). New York: Academic Press.

McHugh, R., \& Morgan, J. N. (1984). The determinants of interstate student migration: A place-to-place analysis. Economics of Education Review, 3(4), 269-278.

Middendorff, E., Apolinarski, B., Poskowsky, J., Kandulla, M., \& Netz, N. (2013). Die wirtschaftliche und soziale Lage der Studierenden in Deutschland 2012; 20. Sozialerhebung des Deutschen Studentenwerks.

Mixon, F. G., \& Hsing, Y. (1994). College student migration and human capital theory: A research note. Education Economics, 2(1), 65-73.

Montgomery, M. (2002). A nested logit model of the choice of a graduate business school. Economics of Education Review, 21, 471-480.

Murdock, J. (2006). Handling unobserved site characteristics in random utility models of recreation demand. Journal of Environmental Economics and Management, 51, 1-25.

Niu, S. X., \& Tienda, M. (2008). Choosing colleges: Identifying and modeling choice sets. Social Science Research, 37, 416-433.

Non, A., \& Tempelaar, D. (2016). Time preferences, study effort, and academic performance. Economics of Education Review, 54, 36-61.

OECD. (2018). Education database: Enrolment by age. OECD Education Statistics (database). https://doi. org/10.1787/71c07338-en, Access date: 07/11/2018.

Oosterbeek, H., Groot, W., \& Hartog, J. (1992). An empirical analysis of university choice and earnings. De Economist, 140(3), 293-309.

Parsons, G. R., \& Hauber, A. B. (1998). Spatial boundaries and choice set definition in a random utility model of recreation demand. Land Economics, 74(1), 32-48.

Pellegrini, P. A., \& Stewart Fotheringham, A. (2002). Modelling spatial choice: A review and synthesis in a migration context. Progress in Human Geography, 26(4), 487-510.

Perkins, R., \& Neumayer, E. (2014). Geographies of educational mobilities: Exploring the uneven flows of international students. The Geographical Journal, 180(3), 246-259.

Pissarides, C. A. (1974). Risk, job search, and income distribution. Journal of Political Economy, 82(6), $1255-1267$.

Pramono, A., \& Oppewal, H. (2012). Accessibility and the role of the consideration set in spatial choice modelling: A simulation study. Journal of Choice Modelling, 5(1), 46-63.

Prazeres, L. (2013). International and intra-national student mobility: Trends, motivations and identity. Geography Compass, 7(11), 804-820.

Roback, J. (1982). Wages, rents and the quality of life. Journal of Political Economy, 90(6), 1257-1278.

Rodríguez González, C., Bustillo Mesanza, R., \& Mariel, P. (2011). The determinants of international student mobility flows: An empirical study on the Erasmus programme. Higher Education, 62, 413-430.

Sá, C., Florax, R. J. G. M., \& Rietveld, P. (2004). Determinants of the regional demand for higher education in The Netherlands: A gravity model approach. Regional Studies, 38(4), 375-392.

Scheller, P., Sören I., \& Sommer, D. (2013). Studienanfängerinnen und Studienanfänger im Wintersemester 2011/12; HIS Forum Hochschule.

Schneider, L., \& Kubis, A. (2010). Are there gender-specific preferences for location factors? A grouped conditional logit-model of interregional migration flows in Germany. Schmollers Jahrbuch, 130, 143-168.

Schündeln, M. (2014). Are immigrants more mobile than natives? Evidence from Germany. Journal of Regional Science, 54(1), 70-95.

Schwartz, A. (1973). Interpreting the effect of distance on migration. Journal of Political Economy, 81(5), 1153-1169.

Sjaastad, L. A. (1962). The costs and returns of human migration. Journal of Political Economy, 70(5), 80-93.

Skinner, B. T. (2019). Choosing college in the 2000s: An updated analysis using the conditional logistic choice model. Research in Higher Education, 60(2), 153-183.

Train, K. E. (2009). Discrete choice methods with simulation (2nd ed.). New York: Cambridge University Press. 
Tversky, A. (1972). Elimination by aspects: A theory of choice. Psychological Review, 79(4), 281-299.

Weisser, R. A. (2016a). MESARAS 2013: Mobility, expectations, self-assessment and risk attitude of students-full version; GESIS Data Archive, Cologne. ZA6294 Data file Version 1.0.0. https://doi. org/10.4232/1.12544.

Weisser, R. A. (2016b). MESARAS 2013: Mobility, expectations, self-assessment and risk attitude of students; project and methodological report, May 2016.

Whisler, R. L., Waldorf, B. S., Mulligan, G. F., \& Plane, D. A. (2008). Quality of life and the migration of the college-educated: A life-course approach. Growth and Change, 39(1), 58-94.

Publisher's Note Springer Nature remains neutral with regard to jurisdictional claims in published maps and institutional affiliations. 